\title{
PERKAWINAN KICAK KACANG MASYARAKAT \\ HINDU KAHARINGAN DI DESA TEWANG TAMPANG \\ KECAMATAN TASIK PAYAWAN KABUPATEN KATINGAN \\ (PERSPEKTIF HUKUM HINDU)
}

Oleh

Mariatie

\begin{abstract}
Abstrak
\end{abstract}
Perkawinan merupakan warisan kodrat manusia dan salah satu dari siklus kehidupan individu, setiap orang yang normal akan sampai dan melewatinya dengan segala macam kepercayaan perlakuan dan harapan. Untuk mewujud tujuan perkawinan tersebut adalah membentuk keluarga yang bahagia dan kekal abadi berdasarkan Ketuhanan Yang Maha Esa.

Dalam upacara perkawinan tidak hanya ada satu jenis perkawinan, namun ada banyak jenis perkawinan. Begitu pula dengan sistem perkawinan masing-masing tidak sama dari prosesi maupun sarana yang digunakan sesuai dengan tradisi dari masing-masing Daerah, selain itu Perkawinan merupakan upacara mempersatukan dua insan laki-laki dan perempuan dalam ikatan suami istri, yang diatur dalam hukum adat/agama dan undang-undang. Perkawinan kicak kacang ini adalah adanya hubungan ikatan batin dari semua mahluk hidup yang berbeda jenis kelamin untuk hidup dan berkembang biak. Namun perkawinan yang dilakukan oleh umat manusia sejak awal, sudah ada hukum dan ketentuannya sesuai agama masing-masing. Dalam kitab suci agama Hindu Kaharingan Panaturan pasal 19 berbunyi : Manyamei Tunggul Garing Janjahunan Laut Dilasksanakan Perkawinan dengan Kameluh Putak Bulau Janjulen Karangan. Ayat 3 menyatakan adalah sesungguhnya mereka berdua ini wujudku sendiri aku akan melaksanakan upacara perkawinannya agar mereka dapat memberikan keturunan berupa aku bagi kehidupan dunia yang aku kehendaki dan ini pula yang mereka lakukan pada kehidupan dunia nantinya.(Tim Penyusunan 2013; 46)

Perkawinan Kicak Kacang ini dilatar belakangi oleh permasalahan antara si perempuan sudah bersatu dengan si laki-laki dalam istilah lain kumpul kebu tinggal satu rumah belum dilakukan upacara pensucian, maka oleh sebab itu dari orang tua pihak perempuan meminta tanggung jawab si laki-laki untuk melakukan upacara Kicak Kacang sebagai pensucian mereka berdua sehingga tidak melakukan perjinahan (dosa sala). Karena mereka berdua suka sama suka tidak ada pemaksaan diantara mereka, seorang lakilaki meminta seorang anak perempuan untuk dijadikan istrinya dan syaratsyarat adat ditetapkan dan dibayar oleh pihak laki-laki pada saat upacara kawin Kicak Kacang, pada saat itu pula dibuat surat perjanjian oleh kedua belah pihak sebagai dasar hukum perkawinan Kicak Kacang.

Kata Kunci: Perkawinan Kicak Kacang Masyarakat Hindu Kaharingan 
*Dosen pada Fakultas Dharma Sastra IAHN-TP Palangka Raya 


\section{Pendahuluan}

Kehidupan di Indonesia umumnya dan kalimantan Tengah pada khususnya dilaksanakan dalam berbagai bentuk dan proses perkawinan dengan urutanurutan yang terkait erat dengan Adat Istiadat setempat. Hal tersebut banyak melahirkan beberapa fenomena sosial religius dan sosial kemasyarakatan Agama Hindu Kaharingan yang patut untuk diteliti, guna menghindari karya tulis ilmiah yang kini masih dirasakan masih kurang baik secara kuantitas maupun kualitas.

Perkawinan menurut Hindu sangat dimuliakan, karena dalam setiap perkawinan dipandang sebagai suatu jalan untuk melepaskan derita orangtuanya, (leluhurnya) diwaktu mereka telah meninggal. Karena itu perkawinan dan dilahirkannya anak (suputra) merupakan perintah agama yang dimuliakan.

Keluarga yang bahagia kekal abadi dapat dicapai apabila dalam rumah tangga terjadi keharmonisan serta keseimbangan hati dan kewajiban antara suami dan isti. Keduanya harus saling isi mengisi antara satu dengan yang lainnya saling bahu membahu dalam membina rumah tangga , saling menyayangi, saling memperhatikan kehendak masing-masing menyatukan dua pribadi yang berbeda antara suami dan istri memerlukan perhatian yang sangat bijaksana.

Tujuan orang membentuk rumah tangga adalah membentuk keluarga yang bahagia/sukinah) sesuai pasal Undang-Undang perkawinan no 1 tahun 1971 yaitu perkawinan adalah ikatan lahir batin antara seorang pria dengan seorang wanita sebagai suami istri dengan tujuan untuk membina rumah tangga yang kekal bahagia berdasarkan ketunahan yang maha esa, maka dalam agama Hindu sebagaimana diutarakan dalam kitab suci Veda perkawinan adalah terbentuknya sebuah keluarga yang berlangsung sekali dalam hidup manusia. Hal tersebut disebutkan dalam kitab Manava Dharmasastra IX. 102 sebagai berikut:

(102) "Tatha nityam yateyam stripumsau tu kritakriyau, Jatha nabhicaretam tau wiyuktawitaretaram", 
Artinya:

"Hendaknya laki-laki dan perempuan yang terikat dalam ikatan perkawinan, mengusahakan dengan tidak jemu-jemunya supaya mereka tidak bercerai dan jangan hendaknya melanggar kesetiaan antara satu dengan yang lain" (Pudja, dan Tjokorda Rai Sudharta, 2002: 553).

Berdasarkan sloka di atas nampak jelas bahwa agama Hindu tidak menginginkan adanya perceraian. Bahkan sebaliknya, dianjurkan agar perkawinan yang kekal hendaknya dijadikan sebagai tujuan tertinggi bagi pasangan suami istri. Dengan terciptanya keluarga bahagia dan kekal maka kebahagiaan yang kekal akan tercapai pula. Ini sesuai dengan ajaran Veda dalam kitab Manava Dharma sastra III. 60, sebagai berikut:

"Samtusto bharyaya bharta bharta tathaiva ca, sminnewa kule nityam kalyanam tatra wai dhruwam", Artinya:

"Pada keluarga dimana suami berbahagia dengan istrinya dan demikian pula sang istri terhadap suaminya, kebahagiaan pasti kekal" ( Pudja dan Tjokorda Rai Sudharta, 2002: 148).

Dengan demikian dapat disimpulkan bahwa tujuan perkawinan menurut agama Hindu adalah mendapatkan keturunan dan menebus dosa para orang tua dengan menurunkan seorang putra yang suputra sehingga akan tercipta keluarga yang bahagia di dunia (jagadhita) dan kebahagiaan kekal (moksa).

\section{PEMBAHASAN}

A Tata cara perkawinan kicak kacang masyarakat Hindu Kaharingan.

Menurut hasil wawancara dengan Gagas Diul selaku pengurus MKAHK Desa Tewang Tampang bahwa tata cara perkawinan Kicak Kacang masyarakat Hindu Kaharingan dilakukan dengan beberapa tahapan sebagai berikut :

1. Musyawarah kedua belah pihak

Musyawarah adalah merupakan proses awal dalam menyelesaikan suatu masalah yang telah dilakukan oleh kedua belah pihak. Musyawarah menurut bahasa berarti "berunding" dan "berembuk", sedangkan pengertian musyawarah menurut istilah adalah perundingan bersama antara dua orang 
atau lebih untuk mendapatkan keputusan yang terbaik. Musyawarah adalah pengambilan keputusan bersama yang telah disepakati dalam memecahkan suatu masalah. Dalam hal ini masalah seorang perempuan dengan seorang laki telah melakukan perjinahan yaitu kumpul kebu dalam satu rumah yang melanggar norma agama, maka perlu dilakukan musyawarah dan mufakat mencari solusi dalam penyelesaian terhadap kasus tersebut. Sehingga hasil keputusan bersama kedua belah pihak adalah kedua pasangan tersebut harus dilakukan upacara pensucian menurut aturan agama yang dianut mereka yaitu melakukan upacara Nyaki Malas yang dilakukan perkawinan Kicak Kacang menurut aturan agama Hindu Kaharingan.

\section{Persiapan sarana upacara Nyaki Kicak Kacang}

Pada upacara Nyaki Kicak Kacang memerlukan sarana prasarana untuk kelengkapan upacaranya seperti tikar (amak pasar), darah ayam atau darah babi, tampung tawar, beras hambaruan diletakan dalam mangkok kecil yang berisikan beras, giling pinang dan rukun tarahan, Sirau/Lilis Lamiang, minyak kelapa (undus tanak), batu asah tempat berpijak, Daun Sawang, baram/tuak. Sarana upacara sangat sederhana tetapi mengandung makna yang sangat mendalam bagi kedua pasangan yaitu pemberkatan doa, sehingga mereka disucikan menurut hukum agama Hindu Kaharingan.

\section{Pelaksanaan Upacara Perkawinan Kicak Kacang}

Pelaksanaan Upacara Perkawinan Kicak Kacang dilakukan sangat sederhana tingkat Kanista, karena tidak mengundang orang banyak akan tetapi yang diundang adalah pengurus desa antara lain mantir adat, kepala desa, tokoh masyarakat, tokoh agama yaitu ketua Majelis Kelompok Agama Hindu Kaharingan, pisor dan keluarga kedua belah pihak dari pihak lakilaki dan keluarga pihak perempuan agar ikut untuk menyaksikan upacara perkawinan tersebut, untuk sama-sama memberikan restu kepada calon mempelai tersebut yang akan melaksanakan perkawinan Kicak Kacang.

Pelaksanaan upacara perkawinan Kicak Kacang dilakukan secara sederhana akan tetapi sah menurut Hukum Agama Hindu, karena ada 
telatah (tata cara) yang mengatur jalannya upacara tersebut, dengan pelaksanaan sebagai berikut :

a. Membicarakan Jalan Hadat si Perempuan yang akan disiapkan oleh pihak laki-laki.

b. Kedua mempelai membacakan surat perjanjian/kontrak perkawinan di hadapan para saksi dan orang tua.

c. Pelaksanaan upacara Nyaki Malas oleh kedua orang tua baik dari pihak laki-laki maupun orang tua pihak perempuan dan pisor yang memimpin upacara.

Demikian juga menurut Susilo selaku Pisor Agama Hindu Kaharingan di Desa Tumbang Panggo menjelaskan pada jaman dulu Kawin Kicak Kacang harus menggunakan darah babi sebagai salah satu syarat pensuciannya, sedangkan pada jaman sekarang ada mengalami perubahan yaitu pada saat acara Nyaki Malas kedua pasangan tersebut bisa digunakan dengan darah ayam atau telor ayam kampong karena menyesuaikan kemampuan dana kedua belah pihak dan apabila memang kemapuan dananya ada tidak salahnya menggunakan babi sesuai dengan kemapuan dan kesepakatan dari pihak keluarga laki-laki maupun perempuan. Kawin Kicak Kacang adalah perkawinan yang dilaksanakan secara sederhana dan apabila ada kemampuan berikutnya dapat dilakukan secara lebih besar dengan resepsinya dan begitu pula sebaliknya apabila tidak ada kemampuan dana untuk melaksanakannya cukup dengan upacara Kawin Kicak Kacang, karena perkawinan tersebut juga adalah syah secara agama Hindu Kaharingan (wawancara tgl, 25 Mei 2017).

Menurut Mandau selaku mantir adat menyatakan bahwa perkawina Kicak-Kacang itu bisa dikatakan sah apabila sudah dilakukan upacara pensucian dengan Nyaki Malas sebagai upacara yang sakral dan direstuai Ranying Hatalla/Tuhan Yang Maha Esa, dan mereka berdua sudah dikatan suami istri bisa tinggal dalam satu rumah, karena sudah melaksanakan perkawinan adat Kicak-Kacang tersebut. dan tetap menggunakan jalan hadat/jujuran, perkawinan ini bukan semata mata untuk kepentingan kedua 
colan mempelai ataupun pihak keluarga tetapi juga menyangkut adat dan tradisi kampung tersebut agar menjaga kerhormatan dan tidak menimbulkan pali (marapetaka dikampung tersebut). Karena pada saat pelaksanaan perkawinan tersebut selain kehadiran dari pihak keluarga calon menpelai laki-laki maupun perempuan juga dihadiri oleh masyarakat,mantir adat, pisor, juga diketahui oleh Kepala Desa Tewang Tampang (wawancara tgl 25 Mei 2017)

Menurut Prihatin selaku Ketua Majelis Kelompok Agama Hindu Kaharingan di Desa Tewang Tampang menyatakan tata cara perkawinan kicak kacang masyarakat Hindu Kaharingan di Desa Tewang Tampang adalah dilakukan karena ada seorang perempuan bernama Normala Sari telah dipinang oleh seorang laki-laki yang bernama Acon yang beralamat di Desa Tewang Tampang, maka berdasarkan kesepakatan bersama kedua belah pihak melakukan perkawinan tingkat yang sederhana (kanista) yang disebut Kawin Kicak Kacang, karena tidak ada kemampuan dana untuk melangsungkan perkawinan ditingkat madya atau utama, dari hasil kesepakatan tersebut orang tua pihak perempuan memberitahukan kepada ketua Majelis Kelompok Agama Hindu Kaharingan (MK-AHK) Desa Tewang Tampang, untuk melaksanakan upacara perkawinan Kicak Kacang sesuai dengan aturan agama Hindu Kaharingan, dan selanjutnya diberitahukan kepada Kepala Desa (wawancara tgl. 26 Mei 2017).

Berdasarkan hasil wawancara dengan narasumber diatas dapat disimpulkan bahwa tata cara perkawinan kicak kacang masyarakat Hindu Kaharingan di Desa Tewang Tampang adalah dilakukan dengan upacara Nyaki Malas kedua pasangan tersebut disaksikan oleh orang tua ahli waris, Kepala Desa, Ketua Majelis Kelompok Agama Hindu Kaharingan dan pisor yang melaksanakan upacara ritual. Perkawinan adalah ikatan lahir batin antara seorang pria dengan seorang wanita sebagai suami istri dengan tujuan membentuk keluarga (rumah tangga) yang bahagia yang kekal berdasarkan Ketuhanan Yang Maha Esa, dengan dilakukan Kawin Kicak 
Kacang pada kedua pasangan tersebut sudah syah menurut agama Hindu Kaharingan.

Upacara-upacara tradisional di Kalimantan Tengah merupakan suatu mata rantai yang tak dapat dipisahkan dari Tattwa yang merupakan inti dari pada ajaran agama Hindu Kaharingan (tradisi religi asli masyarakat Hindu Kaharingan) dengan susila yang merupakan aturan-aturan yang patut dilaksanakan untuk mencapai tujuan. Unsur tattwa, etika dan upacara merupakan unsur universal ajaran agama Hindu Kaharingan yang terkandung dalam setiap ritual yang dilakukan oleh masyarakat Dayak Kalimantan Tengah Khususnya masyarakat Desa Tewang Tampang.

Masyarakat Hindu Kaharingan sangat kaya dengan upacara-upacara keagamaan antara lain seperti tata cara perkawinan pada masyarakat Hindu Kaharingan yang disebut "Pelek Rujin Pangawin. Ritual upacara perkawinan merupakan salah satu ritual keagamaan yang dianggap adat leluhur yang dilakukan secara turun temurun oleh umat Hindu Kaharingan seperti Kawin Kicak Kacang pada jaman dulu sering dilakukan, karena melaksanakan perkawinan yang sangat sederhana menyesuaikan keadaan ekonomi keluarga.

Tata cara perkawinan yang keterkaitan dengan keyakinan masyarakat Hindu Kaharingan yaitu upacara Manyaki Malas Panganten (pengukuhan perkawinan) baik perkawinan Kicak Kacang maupun perkawinan yang dilakukan sesuai dengan pelek rujin pangawin. Secara dasariah ritual perkawinan masyarakat Hindu Kaharingan tingkat utama terbentuk dari beberapa bagian yang sudah terpola dalam satu kesatuan secara keseluruhan yang terdiri dari Hakumbang Auh (peminangan), Hisek (penentuan tanggal pelaksanaan perkawinan beserta persyaratan/Jalan Hadat dan perjanjian perkawinan), Mamanggul, Mananggar Janji dan pelaksanaan Upacara Perkawinan, seperti Hasaki Hapalas (pengukuhan/pemberkatan perkawinan menurut tata cara yang sudah diwariskan oleh leluhur). Ranying Hatalla/Tuhan Yang Maha Esa menurunkan ajaran-Nya melalui Raja Uju Hakanduang agar melaksanakan ritual perkawinan bagi Raja Garing Hatungku 
dengan Kamelus Endas Bulau Lisan Tingang serta pada perkawinan Manyamei Tunggul Garing Janjahunan Laut dengan Kameluh Putak Bulau Janjulen Karangan, yang mana kedua manusia tersebut menurut keyakinan masyarakat Hindu Kaharingan merupakan cikal bakal manusia pertama yang menjadi contoh bagi kehidupan keturunan raja bunu yang hidup di dunia. Berdasarkan dari contoh perkawinan yang dilakukan oleh Nyai Endas Bulau Lisan Tingang dengan Raja Garing Hatungku tersebut sangat jelaslah bahwa upacara kawin Kicak Kacang bagi masyarakat Hindu Kaharingan di Desa Tewang Tampang sesuai Talatah yang telah diajarkan dari sejaman dulu oleh Bawi Ayah dan sah menurut ajaran agama Hindu Kaharingan. Upacara kawin Kicak Kacang sering dilakukan oleh masyarakat di tingkat pedesaan, karena pelaksanaan sangat sederhana dan tidak terlalu banyak mengeluarkan biaya.

Dari hasil pembahasan diatas dapat disimpulkan bahwa tatacara perkawinan Kicak Kacang merupakan upacara yang bersifat sakral menurut agama Hindu Kaharingan sesuai teori Religi yang mengungkapkan tentang Sistem upacara keagamaan secara khusus mengandung empat aspek yaitu: (a) tempat upacara keagamaan dilakukan; (b) saat-saat upacara keagamaan dijalankan; (c) benda benda dan alat upacara; (d) orang-orang yang melakukan dan memimpin upacara. Teori Religi dapat membedah dari hasil penelitian tentang pekawinan Kicak Kacang masyarakat Hindu Kaharingan.

\section{B. Perkawinan Kicak Kacang masyarakat Hindu Kaharingan di Desa} Tewang Tampang perspektif Hukum Hindu.

Menurut Prihatin selaku Ketua Majelis Kelompok Agama Hindu Kaharingan (MK-AHK) Desa Tewang Tampang menjelaskan tentang kekuatan hukum perkawinan Kicak Kacang masyarakat Hindu Kaharingan adalah berdasarkan pelek tatu hyang Nyai Endas Bulau Lisan Tingang (Indu Sangomang) dengan Raja Garing Hatungku (bapa sangomang) yang telah tertulis di dalam Kitab suci Panaturan dan pada saat upacara perkawinan Kicak Kacang dilakukan dengan Nyaki Malas sebagai ritual pensucian kedua 
pasangan sdr. Acon dengan Normala Sari yang dilaksanakan oleh pisor sebagai pimpinan upacara dan selanjutnya dibuat surat perjanjian kawin ditanda tangani kedua belah pihak dan disaksikan oleh Saksi dan ahli waris. Surat perjanjian tersebut sebagai kekuatan hukum perkawinan Kicak Kacang bagi Sdr. Acon dengan Normala Sari, karena isi dari perjanjian tersebut telah memuat 5 (lima) pasal sebagai berikut :

(1) Saya ACON, mengambil NORMALA SARI menjadi Istri saya dan saya cintai kepadanya serta memelihara dia dalam suka dan duka serta tidak menceraikan dia sampai mati.

(2) Jikalau oleh kejahatan saya, saya mengambil perempuan lain, itu adalah terhitung saya menceraikan dia, maka saya harus membayar denda sebesar Rp.5.000.000,- (Lima Juta Rupiah) kepada istri saya.

(3) Segala harta benda pendapatan kami berdua selama kami sudah kawin/menikah dibagi 2 (dua), setengah bagian untuk istri saya.

(4) Jikalau saya meninggal dunia, maka ahli waris saya berhak menerima setengah bagian dari pendapatan/harta kami berdua, tetapi kalau saya mempunyai anak, maka anak saya menerima bagian itu dan ahli waris tidak berhak menerimanya.

(5) Saya Normala Sari, mengaku benar semua perjanjian suami saya diatas serta berjanji juga menurut yang suami saya telah berjanji dari pasal $1 \mathrm{~s} / \mathrm{d}$ 4 diatas tadi.

Dari kelima bunyi pasal tersebut diatas memberikan kekuatan hukum yang mengikat kedua pasangan tersebut untuk menuju kehidupan berumah tangga yang bahagia (wawancara tgl. 3 Juni 2017).

Menurut Acon dan Normala Sari selaku pelaku dalam perkawinan Kicak Kacang menyatakan bahwa dia melakukan perkawinan Kicak Kacang tersebut karena mereka berdua milih perkawinan Kicak Kacang selain berhubungan dengan masalah dana, karena perkawinan tersebut memang sudah turun temurun dilaksanakan karena perkawinan Kicak Kacang adalah syah menurut adat maupun agama Hindu Kaharingan. Jadi menurut mereka berdua tidak salah apabila masyarakat melaksanakan perkawinan kicak 
kacang itu walaupun dibilang sederhana dan sangat singkat tetapi tetap ada yang harus dipenuhi syarat agar melaksanakan perkawinan tersebut, ada disiapkan ayam, telor ayam, tampung tawar, untuk mendinginkan pada saat mereka berdue duduk berdampingan (munduk habambai) disitu masingmasing dari pihak keluarga mereka berdua untuk dilakukan manyaki malas (wawancara tgl. 5 Juni 2017).

Berdasarkan hasil wawancara narasumber tersebut diatas dapat disimpulkan bahwa proses perkawinan masyarakat Hindu Kaharingan yang menjadi sumber Hukum Hindu dalam pelaksanaan perkawinan adalah agama atau kepercayaan sebagaimana yang terdapat dalam Kitab Panaturan pasal 30 yaitu tentang perkawinan "Kameluh Endas Bulau Lisan Tingang Matuh kabaluma Belum, pada ayat 26 sebagai berikut:

RANYING HATALLA, hemben te mameteh; lalus awi ketun gawi akan Raja Garing Hatungtu, hete ketun mamelek Sinde Uju tuntang AKU kereh atun hadurut manalih gawin te, awi ie hajanji taharep $A K U$

Artinya :

Pada saat itu RANYING HATALLA berfirman : laksanakan oleh kalian upacara itu (ritual perkawinan) untuk Raja Garing Hatungku, disana kalian mamelek sinde uju dan nanti AKU akan datang pada upacara itu, karena mereka berdua berjanji dihadapanKu. (Panaturan, 2013 : 109).

Dengan memahami apa yang dijelaskan pada Panaturan pasal 30 ayat 26 di atas, kita dapat mengetahui bahwa kekuatan Hukum perkawinan masyarakat Hindu Kaharingan baik ditingkat sederhana (kanista), sedang (Madya), besar (utama) adalah sesuai ajaran suci Ranying Hatalla yang termuat dalam Kitab Panaturan. Di Panaturan dijelaskan bahwa pada intinya sumpah janji yang diucapkan oleh kedua mempelai pada ritual perkawinan itu diiringi atau diberkati langsung oleh Ranying Hatalla. Dalam setiap ritual yang dilakukan oleh umat Hindu Kaharingan tidak terlepas dari sarana upakara, termasuk juga pada ritual perkawinannya. Sarana upakara ini syarat dengan simbol-simbol yang mempunyai makna bagi yang melaksanakannya. Karena simbol-simbol tersebut dipergunakan agar orang dapat memahami makna dibalik upacara itu dalam hal ini upacara Nyaki 
Malas menggunakan beberapa sarana dan prasarana. Simbol-simbol tersebut mempunyai nilai religi/sakral yang suci.

Berdasarkan hasil pembahasan tersebut diatas dapat dibedah dengan teori fungsionalisme structural, karena teori tersebut dapat mengutarakan bahwa masyarakat adalah suatu sistem sosial yang terdiri dari bagian dan struktur-struktur yang saling berkaitan dan saling membutuhkan keseimbangan, fungsionalisme struktural lebih mengacu pada keseimbangan. Teori ini menilai bahwa semua sistem yang ada di dalam masyarakat pada hakikatnya mempunyai fungsi tersendiri seperti dalam proses pelaksanaan perkawinan Kicak Kacang bagi masyarakat Hindu Kaharingan ada mempunyai struktur tersendiri seperti proses upacara, sarana prasarana, dan pembuatan surat kawin yang memiliki kewenangan adalah Ketua Majelis Agama Hindu Kaharingan setempat .

\section{KESIMPULAN}

Berdasarkan deskripsi tentang Perkawinan Kicak Kacang Masyarakat Hindu Kaharingan Di Desa Tewang Tampang Kecamatan Tasik Payawan Kabupaten Katingan ( Perspektif Hukum Hindu ) yang telah dipaparkan diatas, ada beberapa hal penting yang dapat disimpulkan :

1. Tata cara perkawinan kicak kacang masyarakat Hindu Kaharingan di Desa Tewang Tampang adalah dilakukan dengan musyawarah kedua belah pihak, persiapan sarana upacara dan pelaksanaan upacara Nyaki Malas kedua pasangan tersebut disaksikan oleh orang tua ahli waris, Kepala Desa, Ketua Majelis Kelompok Agama Hindu Kaharingan dan pisor yang melaksanakan upacara ritual. Perkawinan Kicak Kacang adalah ikatan lahir batin antara seorang pria dengan seorang wanita sebagai suami istri dengan tujuan membentuk keluarga (rumah tangga) yang bahagia yang kekal berdasarkan Agama dan Kepercayaan, dengan dilakukan Kawin Kicak Kacang pada kedua pasangan tersebut sudah syah menurut agama Hindu Kaharingan.

2. Kekuatan Hukum Perkawinan Kicak Kacang masyarakat Hindu Kaharingan di Desa Tewang Tampang adalah agama atau kepercayaan 
sebagaimana yang terdapat dalam Kitab Panaturan pasal 30 yaitu tentang perkawinan "Kameluh Endas Bulau Lisan Tingang Matuh kabaluma Belum, berdasarkan pelek tatu hyang Nyai Endas Bulau Lisan Tingang (Indu Sangomang) dengan Raja Garing Hatungku (bapa sangomang) upacara perkawinan Kicak Kacang dilakukan dengan Nyaki Malas sebagai ritual pensucian kedua pasangan sdr. Acon dengan Normala Sari yang dilaksanakan oleh pisor sebagai pimpinan upacara dan selanjutnya dibuat surat perjanjian kawin ditanda tangani kedua belah pihak dan disaksikan oleh Saksi dan ahli waris. Surat perjanjian tersebut sebagai kekuatan hukum perkawinan Kicakicak Kacang bagi Sdr. Acon dengan Normala Sari, karena berisikan 5 pasal tentang perjanjian kedua mempelai tersebut.

Berdasarkan kesimpulan diatas, maka ada beberapa saran yang perlu penulis sampaikan :

1. Disarankan kepada seluruh umat Hindu Kaharingan dan pimpinan lembaga adat, agama dan tokoh masyarakat Desa Tewang Tampang Kecamatan Tewang Sanggalang Garing Kabupaten Katingan sering memberikan pembinaan kepada umatnya demi peningkatan pengetahuan keagamaan, karena secara umum masyarakat Hindu Kaharingan di Desa Tewang Tampang masih banyak yang belum memahami tentang tata cara perkawinan Kicak Kacang yang dilaksanakan oleh masyarakat Hindu Kaharingan.

2. Disarankan kepada seluruh masyarakat Hindu Kaharingan pada khususnya dan masyarakat Kalimantan Tengah pada umumnya, hendaknya jangan dulu menganggap bahwa upacara perkawinan bukan sekedar saja untuk memberikan kebahagiaan pada seseorang, akan tetapi hikmah dari upacara tersebut adalah suatu ketulusan, keiklasan yang dipersembahkan dalam mencapai kesucian yang abadi.

\section{DAFTAR PUSTAKA}


Iqbal, Hasan. 2002. Pokok-Pokok Materi Penelitian dan Aplikasi. Indonesia: Ghalia.

Kiwok D Rampai.1994. Adat dan Upacara Perkawinan Daerah Kalimantan Tengah. Palangka Raya: DEPDIKBUD-Kalteng.

Maman, Kh. 2006. Metodologi Penelitian Agama. Jakarta: PT. Raja Grafindo Perkasa.

Moleong, lexy J.2009.Metodelogi Penelitian Kualitatif.Bandung:PT Remaja Rosdakarya.

Offeni.2010. Tesis"Upacara Perkawinan Adat Dayak Ngaju di Kelurahan Palangka Raya Kecamatan Jekan Raya Kalimantan Tengah. Denpasar UNHI.

Surpha, I Wayan. 2005. Pengantar Hukum Hindu. Surabaya. Paramita.

Soekanto, 2004. Meninjau Adat Di Indonesia, Jakarta : Soerongan.

Pudja G. dan Tjokorda Rai Sudharta.2002. Manawa Dharmasastra atau Weda Smerti. Jakarta: CV. Nitra Kencana Buana

Tim Penyusun. 2013. Panaturan. Denpasar: Widya Dharma

Perundang-Undangan:

Undang-Undang Perkawinan. 1985. Undang-Undang Nomor 1 Tahun 1974 dan Undang-Undang Nomor 9 Tahun 1975 serta Undang-Undang Nomor 10 Tahun 1983. Surabaya: Pustaka Tinta Mas.

Sumber Internet :

(http://teorifungsionalisme struktural. blogspot. co.id /diakses pada tgl 29-09-2016 pukul 19.00 WIB) 